\title{
Neurological findings spectrum in Celiac disease
}

\author{
Erhan Aksoy ${ }^{1}$, Serap Tiraş-Teber ${ }^{3}$, Aydan Kansu ${ }^{3}$, Gülhis Deda², Ayşe Kartal ${ }^{4}$ \\ ${ }^{1}$ Department of Pediatric Neurology, Dr. Sami Ulus Maternity and Childrens' Health and Diseases Training and Research \\ Hospital; ${ }^{2}$ Division of Pediatric Neurology, and ${ }^{3}$ Pediatric Gastroenterology, Ankara University Faculty of Medicine, \\ Ankara, ${ }^{4}$ Division of Pediatric Neurology, Department of Pediatrics, Selçuk University Faculty of Medicine, Konya, Turkey. \\ E-mail: aksoyerhan24@gmail.com \\ Received: 1 December 2015, Revised: 21 January 2016, Accepted: 4 August 2016
}

SUMMARY: Aksoy E, Tiraş-Teber S, Kansu A, Deda G. Kartal A. Neurological findings spectrum in Celiac disease. Turk J Pediatr 2016; 58: 233-240.

We aimed to provide early diagnosis by determining possible Celiac disease related subclinical or symptomatic neurological abnormalities in children in order to decrease risk of mortality and morbidity.

Children with Celiac disease were assessed with neurological examination, neurophysiological tests and neuroimaging.

A total of 65 patients were included in the study. The neurological examination was abnormal in 4 patients. There were EEG abnormalities in 5 patients, VEP was abnormal in 7 patients, BAER was abnormal in 1 patient, ENMG was abnormal in 8 patients, and there were abnormal findings on neuroimaging in 2 patients.

The Celiac disease related neurological complications that manifest in adulthood usually lay their foundations in childhood. Therefore, it must be kept in mind that subclinical neurological abnormalities may be related to Celiac disease, and Celiac disease may be the underlying cause in the patients with overt neurological abnormalities in childhood.

Key words: celiac disease, neurophysiologic study, neuroimaging, children.

Celiac disease (CD) is a chronic autoimmune disorder characterized by $\mathrm{T}$ cell-mediated inflammatory injury of small intestine mucosa in individuals with genetic susceptibility (HLA DQ2 or DQ8) to gluten component found in cereals including wheat, barley, and rye. $\mathrm{CD}$ has four forms including "typical" form accompanied by gastrointestinal symptoms such as diarrhea, malabsorption, and weight loss; "atypical" form accompanied by extraintestinal symptoms including the neurological symptoms; "silent" form accompanied by positive serology and injury to small intestine mucosa; and "potential" form accompanied by normal histological findings despite a positive serology. There is a decrease in statement of CD as a factor of neurological anormalities in the recent twenty years (due to wide-spreading of serological tests and small intestine biopsies). Ataxia, peripheral neuropathy, epilepsy (with or without calcification), migraine, multiple sclerosis, myopathy, myelopathy, hearing loss, white matter and basal ganglion lesions, dystonia and extrapyramidal symptoms, tremor, ophthalmoplegia, optic neuritis, neurodegenerative diseases, brainstem encephalitis, learning difficulties, behavior disturbances, and cerebral/cerebellar atrophy may be seen as neurological abnormalities ${ }^{1-9}$.

In cases of subclinical neurological disorders or overt neurological symptoms without any defined underlying cause, neurophysiological tests [Electroencephalography-EEG, Electroneuromyography-ENMG, Visual Evoked Potential_-VEP, Brainstem Auditory Evoked Potential -BAEP], and neuroimaging methods-brain CT or MRI] will contribute the diagnosis as much as CD serology and small intestine histology. In this study, we aimed to establish neurological follow-up protocols directed to the future, and shed light to new treatment strategies in patients with $\mathrm{CD}$. 


\section{Material and Methods \\ Patients}

Sixty-five children who had positive small intestine histology for CD, and between 2000 and 2010 followed-up in Pediatric Gastroenterology Department of Ankara University Medical Faculty (AUMF) were retrospectively analyzed (6 patients were diagnosed after the study was planned). CD has been investigated in our clinic from the neurological point of view since a number of subclinical and clinical neurological signs are seen.

The patients included in the study were divided into three groups with respect to their ages, as 4-8 years age group (Group 1), 9-13 years age group (Group 2), and $\geq 14$ years age group (Group 3). The patients were divided into three groups in relation to their clinical presentations: typical form in which gastrointestinal symptoms are in the forefront; atypical form that presents with few or nongastrointestinal symptoms; and silent form in which asymptomatic patients are determined by screening the individuals in the risk group due to positive family history. The patients were divided into two groups in relation with the histopathological classification as mild (stages 1 and 2), and severe (stages 3 ) forms.

The neurological examinations of all patients were performed by an experienced pediatric neurologist (G.D.). It was seen that all patients had EEG, and all patients except one patient had imaging (brain MRI or CT). ENMG, VEP, and BAER could be performed only to the patients that could be reached since this step of the study was planned later. Neurophysiological tests were performed by an experienced neurologist (G.D.) with the help of experienced technicians (S.K., H.Z.).

Celiac disease patients with disorders that may cause neurological abnormalities (liver and kidney failure, type I diabetes, other autoimmune diseases, malnutrition, Down's syndrome) have been excluded since those may cause confusion in the etiology. Parents of all patients gave their written informed consents. Ethics Committee of AUMF approved the study protocol.

\section{Neurophysiologic study}

Electroencephalography records were obtained through the electrodes placed on the scalp between nasion and inion, in accordance with the10-20 system.

Visual Evoked Potential records were obtained as follows: the active electrode was placed 5 $\mathrm{cm}$ above the inion, the reference electrode was placed to FPZ (above nasion). The latency and amplitude of the first recorded P100 wave were measured. In VEP, individual data above the age-matched reference P100 latency values were regarded as abnormal, and graded between mild and significantly prolonged latency spectrum.

Brainstem Auditory Evoked Potential records were obtained by placing the active electrode to $\mathrm{C}_{\mathrm{Z}}$ (vertex), and the reference electrode to ear, and giving auditory click stimuli with earphones. Each stimulus (respectively 80, 60 and $50 \mathrm{~dB}$ ) resulted in successive 5 positive waves in the first $10 \mathrm{~ms}$. The latencies of 5 waves (including inter-wave latencies) above the reference values were regarded as abnormal.

Electroneuromyography responses were analyzed in two parts; nerve conduction studies and needle EMG. Nerve conduction velocity (NCV) was measured in motor and sensory nerves (Slower than normal NCV - demyelinating neuropathy). In needle EMG, distal and proximal muscle groups were compared, and motor unit potentials were analyzed. Accordingly, neuropathies were graded as mild axonal, axonal, and severe axonal neuropathies.

\section{Statistical Analysis}

The data were analyzed with SPSS 15.0 package program. Descriptive statistics, Chi-square test, T-test and Mann-Whitney $U$ test were used for statistical analysis of the data, and $\mathrm{P}<0.05$ was considered as statistically significant.

\section{Results}

Sixty-five patients [39 females (60\%), and 26 males (40\%)] were included in the study. Demographic data, presentation (typical, atypical, silent forms), histopathological classification, tissue typing, laboratory findings, and neurological features are presented in Table I.

The mean age of all patients was $12.85 \pm 4.23$ (age range 4-18) years. When the age groups were taken into consideration, there were 12 patients in group 1, 21 patients in group 2, and 32 patients in group 3 . The patients were 
divided into groups in relation to their clinical presentations, and 38 patients had the typical form, 18 patients had the atypical form, and 9 asymptomatic patients had the silent form (Table I).

The neurological findings were normal in 49 patients, however 16 patients had abnormalities (Table II). Thirteen of them were older than 9 years of age (9 patients $>14$ years). Some patients had neurological abnormalities on more than one test (Table III, IV). The age and the age at the time of diagnosis increased the risk of neurological findings, however this result did not reach statistical significance. On the other hand, the mean time between diagnosis of $\mathrm{CD}$ and abnormalities detected on neurophysiological tests (EEG, ENMG, VEP) was 4 years (Table IV). Neurological examination was abnormal in 4 patients $(6.1 \%)$. All those patients were older than 9 years of age ( 3 patients $>14$ years, Tables III, IV).

There were abnormal EEG findings in 5 patients $(7.7 \%)$. Four patients had focal (temporal lobe in 2, occipital lobe in 1, and left hemisphere in 1 newly diagnosed patient with CD), and 1 patient had generalized epileptic activity. Apart

Table I. Characteristics of Patients

\begin{tabular}{|c|c|}
\hline $\begin{array}{l}\text { Number, } \mathrm{n} \\
\text { Sex }(\mathrm{F} / \mathrm{M}), \mathrm{n} / \mathrm{n} \\
\text { Mean age (year), mean } \pm \mathrm{SD} \\
\text { Mean age at diagnosis (year), mean } \pm \mathrm{SD} \\
\text { GFD (mooth), median (min-max) }\end{array}$ & $\begin{array}{c}65 \\
39 / 26 \\
12.85 \pm 4.23 \\
8.39 \pm 4.17 \\
8(1-84)\end{array}$ \\
\hline $\begin{array}{l}\text { Typical presentation, } \mathrm{n}(\%) \\
*[\text { diarrhea }(20), \text { abdominal pain (18), bloating }(5) \text {, constipation }(7)] \\
\text { Sex }(\mathrm{F} / \mathrm{M}), \mathrm{n} / \mathrm{n} \\
\text { Mean age (year), mean } \pm \mathrm{SD} \\
\text { Mean age at diagnosis (year), mean } \pm \mathrm{SD}\end{array}$ & $\begin{array}{c}22 / 16 \\
12.6 \pm 4.42 \\
7.63 \pm 4.36\end{array}$ \\
\hline $\begin{array}{l}\text { Atypical presentation }(\mathrm{n}) \\
*[\text { iron-unresponsive anemia }(10), \\
\text { short stature }(18), \text { hypertransaminasemia }(4), \\
\text { neurological symptoms }(1)]\end{array}$ & $18(27 \%)$ \\
\hline $\begin{array}{l}\text { Sex }(\mathrm{F} / \mathrm{M}), \mathrm{n} / \mathrm{n} \\
\text { Mean age (year), mean } \pm \mathrm{SD} \\
\text { Mean age at diagnosis (year), mean } \pm \mathrm{SD}\end{array}$ & $\begin{array}{c}12 / 6 \\
13.2 \pm 4.09 \\
9.97 \pm 3.15\end{array}$ \\
\hline $\begin{array}{l}\text { Silent presentation }(\mathrm{n}) \\
\text { [positive family history] }\end{array}$ & $9(15 \%)$ \\
\hline $\begin{array}{l}\text { Sex }(\mathrm{F} / \mathrm{M}), \mathrm{n} / \mathrm{n} \\
\text { Mean age (year), mean } \pm \mathrm{SD} \\
\text { Mean age at diagnosis (year), mean } \pm \mathrm{SD}\end{array}$ & $\begin{array}{c}5 / 4 \\
13.1 \pm 4.07 \\
8.4 \pm 4.6\end{array}$ \\
\hline $\begin{array}{l}\text { Histopathologic classification } \\
\text { Mild (Type 1, 2) } \\
\text { Severe (Type 3) }\end{array}$ & $\begin{array}{l}15 \\
50\end{array}$ \\
\hline $\begin{array}{l}\text { Tissue Type (n) } \\
\text { HLA DQ2 } \\
\text { HLADQ8 }\end{array}$ & $\begin{array}{c}30 \\
25 \\
5\end{array}$ \\
\hline $\begin{array}{l}\text { Vitamin B12 levels (n) } \\
\text { Median (min-max) } \\
<200 \mathrm{pg} / \mathrm{ml}(\mathrm{n})\end{array}$ & $\begin{array}{ll}63 \\
263(97-837) \\
22\end{array}$ \\
\hline $\begin{array}{l}\text { Folic acid levels (n) } \\
\text { Median }(\min -\max ) \\
<1.5 \mathrm{ng} / \mathrm{ml}(\mathrm{n})\end{array}$ & $\begin{array}{l}62 \\
7.04(1-32) \\
6\end{array}$ \\
\hline $\begin{array}{l}\text { Positive serology(n) } \\
\text { EMA (IgA/IgG) } \\
\text { TGA (IgA/IgG) } \\
\text { AGA (IgA/IgG) }\end{array}$ & $\begin{array}{c}36 / 5 \\
32 / 6 \\
22 / 27\end{array}$ \\
\hline
\end{tabular}

*Some patients presented with more than one clinical presentation (dominant symptom considered), F: female; GFD: Gluten-free diet; M: male. 
from a patient diagnosed at 5 years of age, all other patients were older than 14 years of age (Table III). The mean age of the patients with abnormal EEG findings were greater when compared to the ones with abnormal findings on other neurophysiological tests (15.25 \pm 4.36 years) (Table IV). However, there were no disease-specific intracranial calcifications that could accompany the disease in those patients (they had normal brain CT or MRI).

Seven of 23 patients had abnormalities on VEP $(30.4 \%)$. Six patients with abnormal findings were older than 9 years of age ( 3 patients $>14$ years, Tables III, IV). There were no refractive errors that could cause those prolongations in visual pathways in those 7 patients, and they did not have any organic abnormalities on brain MRI or CT. Only one of 25 patients had abnormalities in BAEP (moderate sensorineural hearing loss).

There were abnormal ENMG findings in 8 of 23 patients $(34.7 \%)$. None of them had neuropathy symptoms (such as absent tendon reflexes and burning sensation, chills, or numbness in hands or feet). Seven patients with abnormal findings were older than 9 years of age (2 patients $>14$ years, Table III, IV).

Six of the typical presentation patients with abnormalities were older than 9 years of age. All atypical presentation patients that had abnormalities were older than 9 years of age. All silent presentation patients with abnormal findings were older than 9 years of age (Tables II, III, IV). Although did not reach statistical significance, age and age at the diagnosis were greater in atypical and silent presentation forms when compared to the typical presentation form (Table II).

Serological test (EMA, TGA and AGA) levels were not measured in all patients. However, serological tests showed no correlations with neurological findings. All patients had histopathological classifications; however there was no correlation with neurological findings. On the other hand, 12 of 16 patients with abnormal neurological signs had stage 3 severe histopathological findings. Tissue typing was performed in 30 patients. HLA DQ2 was positive in 6 of 11 patients with abnormalities, however tissue typing was not performed in other 5 patients.

Vitamin B12, folic acid (in case of deficiency there may be possible neurological complications) levels were not measured in all patients, however there were no neurological abnormalities in the ones with low serum vitamin levels. Comparison of the neurophysiological tests did not reveal any correlation with age, gender, or presentation.

Table II. Comparison of the Patients

\begin{tabular}{lcc}
\hline Features & $\begin{array}{c}\text { Normal } \\
\text { neurological finding }\end{array}$ & $\begin{array}{c}\text { Abnormal } \\
\text { neurological finding }\end{array}$ \\
\hline Patient, n (\%) & $49(75.4 \%)$ & $16(24.6 \%)$ \\
F/M & $28 / 21$ & $11 / 5$ \\
Mean age (year) mean \pm SD & $12.65 \pm 4.4$ & $13.43 \pm 3.72$ \\
Mean age at diagnosis (year) mean \pm SD & $8.12 \pm 4.33$ & $9.2 \pm 3.66$ \\
& & 7 \\
Typical Presentation & 31 & $5 / 2$ \\
Sex (F/M) & $17 / 14$ & $12.57 \pm 4.31$ \\
Mean age (year) mean \pm SD & $12.6 \pm 4.5$ & $7.8 \pm 3.02$ \\
Mean age at diagnosis (year) mean \pm SD & $7.58 \pm 4.65$ & 6 \\
& & $4 / 2$ \\
Atypical Presentation & 11 & $14.0 \pm 3.52$ \\
Sex $(\mathrm{F} / \mathrm{M})$ & $8 / 4$ & $10.41 \pm 2.24$ \\
Mean age(year) mean \pm SD & $12.83 \pm 4.44$ & 3 \\
Mean age at diagnosis(year) mean $\pm S D$ & $9.75 \pm 3.59$ & $2 / 1$ \\
Silent Presentation & & $14.33 \pm 3.51$ \\
Sex (F/M) & 6 & $10.0 \pm 7.0$ \\
Mean age (year) mean \pm SD & $12.5 \pm 4.5$ & \\
Mean age at diagnosis (year) mean $\pm S D$ & $7.6 \pm 3.61$ & \\
\hline
\end{tabular}

F: female; M: male. 
Table III. Spectrum of Neurological Findings

\begin{tabular}{|c|c|c|c|c|c|c|c|c|}
\hline $\begin{array}{l}\text { Patient } \\
\text { No }\end{array}$ & $\begin{array}{c}\text { Gender/age } \\
\text { (years) }\end{array}$ & $\begin{array}{l}\text { Presentation } \\
\text { type }\end{array}$ & $\mathrm{NE}$ & VEP & BAER & ENMG & EEG & $\begin{array}{c}\text { Neuroimaging } \\
\text { (Brain MRI } \\
\text { Or CT) }\end{array}$ \\
\hline 1 & $\mathrm{~F} / 16$ & Typical & $\mathrm{N}$ & $\begin{array}{l}\text { Unilateral, } \\
\text { mild }\end{array}$ & $\mathrm{N}$ & $\begin{array}{l}\text { Axonal np, } \\
\text { distal }\end{array}$ & Generalized & $\mathrm{N}$ \\
\hline 2 & $\mathrm{~F} / 5$ & Typical & $\mathrm{N}$ & $\begin{array}{l}\text { Bilateral, } \\
\text { mild }\end{array}$ & $\mathrm{N}$ & Demyelinating & Focal & $\mathrm{N}$ \\
\hline 5 & $\mathrm{~F} / 14$ & Typical & $\mathrm{N}$ & $\begin{array}{l}\text { Bilateral, } \\
\text { marked }\end{array}$ & $\mathrm{N}$ & $\mathrm{N}$ & $\mathrm{N}$ & $\mathrm{N}$ \\
\hline 7 & $\mathrm{M} / 13$ & Atypical & $\mathrm{N}$ & $\mathrm{N}$ & $\mathrm{N}$ & Axonal np, & $\mathrm{N}$ & $\mathrm{N}$ \\
\hline 13 & $\mathrm{M} / 10$ & Typical & $\mathrm{N}$ & $\begin{array}{l}\text { Bilateral, } \\
\text { mild }\end{array}$ & $\mathrm{N}$ & $\begin{array}{l}\text { Axonal np, } \\
\text { distal, mild }\end{array}$ & $\mathrm{N}$ & $\mathrm{N}$ \\
\hline 18 & $\mathrm{~F} / 18$ & Typical & $\mathrm{N}$ & A & A & A & Focal & $\mathrm{N}$ \\
\hline 24 & $\mathrm{~F} / 11$ & Silent & $\mathrm{N}$ & $\begin{array}{l}\text { Bilateral, } \\
\text { marked }\end{array}$ & $\mathrm{N}$ & $\begin{array}{c}\text { Axonal np, } \\
\text { mild } \\
\text { (proximal+distal) }\end{array}$ & $\mathrm{N}$ & $\mathrm{N}$ \\
\hline 25 & $\mathrm{M} / 14$ & Typical & MR & $\begin{array}{l}\text { Bilateral, } \\
\text { mild }\end{array}$ & $\mathrm{N}$ & $\begin{array}{l}\text { Axonal np, } \\
\text { distal, mild }\end{array}$ & $\mathrm{N}$ & $\mathrm{N}$ \\
\hline 33 & $\mathrm{~F} / 11$ & Typical & $\mathrm{N}$ & $\begin{array}{l}\text { Bilateral, } \\
\text { mild }\end{array}$ & $\mathrm{N}$ & $\mathrm{N}$ & $\mathrm{N}$ & $\mathrm{N}$ \\
\hline 37 & $\mathrm{~F} / 12$ & Atypical & $\begin{array}{l}\text { Ophthalmoplegia } \\
+ \text { dystonia }\end{array}$ & A & SN & Demyelinating & $\mathrm{N}$ & $\begin{array}{c}\text { White matter + } \\
\text { basal ganglion } \\
\text { lesions * }\end{array}$ \\
\hline 38 & $\mathrm{~F} / 9$ & Atypical & $\mathrm{N}$ & $\mathrm{N}$ & $\mathrm{N}$ & $\begin{array}{l}\text { Sensorimotor } \\
\text { axonal np }\end{array}$ & $\mathrm{N}$ & $\mathrm{N}$ \\
\hline 54 & $\mathrm{~F} / 14$ & Atypical & $\mathrm{N}$ & A & A & A & Focal & $\mathrm{N}$ \\
\hline 56 & $\mathrm{M} / 18$ & Silent & $\mathrm{N}$ & A & A & A & $\mathrm{N}$ & $\begin{array}{l}\text { cerebellar } \\
\text { atrophy** }\end{array}$ \\
\hline 58 & $\mathrm{M} / 18$ & Atypical & $\mathrm{N}$ & A & A & A & Focal & $\mathrm{N}$ \\
\hline 60 & $\mathrm{~F} / 14$ & Silent & MR & A & A & A & $\mathrm{N}$ & $\mathrm{N}$ \\
\hline 61 & $\mathrm{~F} / 18$ & Atypical & MR & $\mathrm{N}$ & $\mathrm{N}$ & A & $\mathrm{N}$ & $\mathrm{N}$ \\
\hline
\end{tabular}

A: absent; BAER: brainstem auditory evoked potential; CT: computerized tomography; EEG: electroencephalography; ENMG: electroneuromyography; F: female; M: male; MR: mental retardation; MRI: magnetic resonance imaging; N: normal; NE: neurological examination; np: nöropathy; SN: sensorineural; VEP: visual evoked potential.

\section{Discussion}

Celiac disease is a chronic autoimmune disease, and its prevalence was reported between 0.6 and $1 \%$. The patients with the typical form of the disease constitute only a small part of $\mathrm{CD}$ iceberg. It was supposed that undiagnosed (atypical or silent form) patients are 5-6 fold more in numbers, and form the unseen portion of the iceberg. Most of those undiagnosed patients are the adults that do not have gastrointestinal findings $s^{1,3-9}$. In our study, we found that the probability for neurological abnormalities increased as age and age at diagnosis increased in atypical and silent forms ( $27 \%$ and $15 \%$, respectively) when compared to typical presentation form (58\%) ( $>0.05)$. Cooke $^{10}$ was the first to show CD-related neurological abnormalities in $6 \%$ of the patients. Some others reported this rate as $8-22.5 \%{ }^{11,12}$. On the other hand, Luostarinen et $a{ }^{13}$ reported that the underlying cause was $\mathrm{CD}$ in $7 \%$ of the patients presented with neurological findings.

The neurological abnormalities associated with CD usually show a subclinical course in childhood. Therefore, those patients are not diagnosed with $\mathrm{CD}$ if the disease does not come into the physician's mind, and diagnosis is delayed until adulthood ${ }^{1,3-9}$. Only a few studies investigated the prevalence of neurological abnormalities in children. In one study, the prevalence of subclinical neurological abnormalities was found as $18.8 \%^{8}$. This value was found as $18.5 \%$ in our study. Immunological process starts with the encountering of gluten sensitive $\mathrm{T}$ lymphocyte and deaminated gliadin by gluten and TG2 that was taken in diet with HLA-DQ2 and HLADQ8 molecules in lamina propria of the small intestine. Anti-TG2 antibodies are deposited (such as muscle, central and peripheral nervous 
Table IV. Abnormal Neurological Findings

\begin{tabular}{lcccccc}
\hline & NE & EEG & VEP & BAER & ENMG & Neuroimaging \\
\hline N (\%) & $4(6.1 \%)$ & $5(7.7 \%)$ & $7(30.4 \%)$ & $1(4$ & $8(34.7 \%)$ & $2(3.2 \%)$ \\
Typical P (F/M) & $1(1 /-)$ & $3(3 /-)$ & $6(4 / 2)$ & - & $4(2 / 2)$ & - \\
Atypical P (F/M) & $2(1 / 1)$ & $2(1 / 1)$ & - & $1(1 /-)$ & $3(2 / 1)$ & $1(1 /-)$ \\
Silent P (F/M) & $1(1 /-)$ & - & $1(1 /-)$ & - & $1(1 /-)$ & $1(-/ 1)$ \\
Mean age (year) & $14.50 \pm 2.52$ & $15.25 \pm 4.36$ & $11.57 \pm 3.59$ & 12.0 & $11.25 \pm 3.37$ & $15.00 \pm 4.24$ \\
$\begin{array}{l}\text { Mean age at } \\
\text { diagnosis (year) }\end{array}$ & $11.0 \pm 2.16$ & $\begin{array}{c}10.50(5- \\
16)\end{array}$ & $7.28 \pm 3.54$ & 9.0 & $7.25 \pm 3.10$ & $13.00 \pm 5.66$ \\
\hline
\end{tabular}

BAER: brainstem auditory evoked potential; EEG: electroencephalography; ENMG: electroneuromyography; F: female; M: male; NE: neurological examination; P: presentation; VEP: visual evoked potential.

system) in the small bowel mucosa of patients with gluten sensitivity, even in the absence of enteropathy. Anti-TG2 antibodies could act together with other autoantibodies to cause selective neuronal degeneration. In patients without overt gastrointestinal involvement, serum antibodies to transglutaminase-2 (TG2) can be absent. Such patients typically have antibodies that primarily react with a different transglutaminase isozyme-TG6 in patients with neurological manifestations. Nevertheless we could not study this aspect as we do not have the anti-TG6' kit of our patients 1,3-5,7,11.

The prevalence of epilepsy is $0.5 \%$ in the population, however its prevalence is $5.5 \%$ in patients with $C D^{5,14}$. On the other hand, there may be EEG abnormalities in absence of convulsions in $\mathrm{CD}^{2}$. It was reported that $48 \%$ of children with CD might have abnormal EEG findings ${ }^{15}$. We found this rate as $7.7 \%$ in our study, however we did not observe convulsions in any of our patients. Epilepsy associated with CD may be focal (mostly occipital) or generalized ${ }^{16}$. In our study, we determined that 4 patients with focal and 1 patient with generalized EEG findings. Those patients consisted of 4 females (3 typical, 1 atypical) and one male (atypical), and all were older than 14 years of age except one newly diagnosed one. Use of antiepileptic drugs together with gluten-free diet may decrease frequency of epileptic attacks ${ }^{4,5}, 16$. On the other hand, it was reported that EEG abnormalities improved in a child only with gluten-free diet after 6 months $^{15}$. We found that EEG abnormalities improved in 3 of 4 patients with gluten-free diet and use of antiepileptic drugs. Another patient newly diagnosed with CD and epilepsy was administered antiepileptic drugs and gluten-free diet, and followed up.

Neuropathy can affect different nerve types and is associated with several autoimmune diseases (such as type 1 diabetes mellitus, autoimmune thyroid disease, SLE, Sjögren's syndrome, vitamin deficiency, and pernicious anemia), including $\mathrm{CD}^{4,5,9}$. But we could not determine a cause other than CD. Neuropathy with CD usually appears slowly, a few years after the onset of the disease, and shows a progressive course 4 . We found that neuropathy is most prominent at four years (Table IV). Luostarinen et al. ${ }^{9}$ found the prevalence of neuropathy as $23 \%$ in adult CD patients. We found neuropathy findings in 8 of 23 patients (34.7\%) on ENMG. There are only a few studies that investigated neuropathy in children, and one study reported neuropathy prevalence as $7.4 \%{ }^{8}$. In that study, the mean duration of gluten-free diet was 17 months while this duration was 36 months in our study. It can be thought that distinctive alternative mechanisms' (biological, immunological and genetic factors) differences can play a role in occurrence of subclinical neuropathy in early ages conversely of elder ages in our patients (most frequent ages 9-13) compatible with gluten-free diets (control serological tests normal, no malabsorption or loss in weight). Subclinical electrophysiological neuropathy findings showed variability in our study, in 2 cases demyelinating (in NCV was found slow), in 6 cases axonal (in NCV with decreased amplitude or in needle EMG with increased amplitude or duration of the motor unit potentials) types were seen. Those patients consisted of 5 females (2 typical, 1 atypical, 1 silent), and 3 males (2 typical, 1 atypical), and three of them had mild neuropathy findings. Although there is an increased risk 
for neuropathy even in well-treated CD patients, usually a distal axonal, subclinical course is $\operatorname{seen}^{5,8,9}$. Similarly, there were no neuropathy symptoms in any of 8 patients (subclinical), the findings were more prominent in distal than proximal muscles in four patients. Although some studies reported that neuropathy could develop due to vitamin $\mathrm{B}_{12}$ and folic acid deficiency in patients with $C D^{1,5,7}$, we did not find deficiency of them in any of our patients.

Collin et al. ${ }^{17}$ described CD-related dementia in 5 patients, and reported cerebral atrophy in 4 , and cerebellar atrophy in 1 of them. Vitamin B12 deficiency was determined in 2, and folic acid deficiency was seen in 3 of those patients. In our study, we found cerebellar atrophy only in 1 patient (silent-male, 18 years) on MRI. This patient did not have ataxia or tremor, and had normal vitamin B12 and folic acid levels. CD-related mental disorders, learning difficulties, and deficient cognitive functions have also been reported 7,18 . Three patients included in our study had mental retardation. Those 3 patients consisted of 2 females ( 1 atypical, 1 silent) and one male (typical), and all were older than 14 years of age. Neuroimaging and blood tests, except for celiac serology, were normal in those patients. One patient (atypical-female) had ophthalmoplegia, extrapyramidal symptoms (dystonia and basal ganglion involvement), demyelinating neuropathy, sensorineural hearing loss, and white matter lesions may be seen in relation with $C D^{6,7,19-21}$. Also sera from patients with $\mathrm{CD}$ and neurological manifestations also evoke a mitochondrial-dependent apoptosis in vitro, suggesting that neurotoxic antibodies might be present ${ }^{22}$.

Complications that may affect visual pathways such as optic neuritis, multiple sclerosis, and occipital calcifications may develop in $\mathrm{CD}^{4,7}$. Therefore, it is clear that VEP may give information about subclinical abnormalities in $C D$ patients with normal neuroimaging and eye examination, and provide insight into pathophysiology of abnormalities related to visual pathways in $\mathrm{CD}$. We found slightly longer, abnormal VEP results in $30.4 \%$ of the patients in our study (most of them slightly prolonged), but we did not find any studies to compare our results. Those patients consisted of 5 females ( 3 typical, 1 atypical, 1 silent) and
2 (typical) males, and 6 of them were older than 9 years of age.

In conclusion, the prevalence of neurological manifestations in $\mathrm{CD}$ is striking and must be considered. In our patients with CD common different neurological findings were seens $18.5 \%$ subclinical, $6.1 \%$ clinical). Furthermore we determined that the mean duration between the age at the diagnosis and abnormalities detected on neurophysiological tests was 4 years in our patients with neurological findings despite that they adhered gluten-free diet (their serum TGA levels were normal and did not have signs of malabsorption on their follow-up). The majority of neurological abnormalities are subclinical and those were determined on neurophysiological tests and neuroimaging should be followed-up due to risk of conversion to overt neurological abnormalities in adulthood. In our study, we also showed increased risk for neurological abnormalities in atypical and silent forms that involve older ages and older ages at the time of diagnosis, and this finding indicated that neurological abnormalities related to CD might be seen in adulthood in those forms when compared to the typical form. Gluten-free diet had resolved intestinal symptoms, but had not prevented the development of neurological deficits more than accidental ${ }^{6}$. Modulation of the immune system might also be possible in the future (via anticytokine therapy or vaccination to gluten epitopes ${ }^{4)}$. Therefore, it is clear that the neurological abnormalities found in our study will shed light to new treatment modalities in $\mathrm{CD}$, in addition to gluten-free diet.

\section{REFERENCES}

1. Tovoli F, Masi C, Elena G, Guidetti E, Negrini P, Bolondi L. Clinical and diagnostic aspects of gluten related disorders. World J Clin Cases 2015; 3: 275-284.

2. Parisi P, Principessa L, Ferretti A, et al. "EEG abnormalities" may represent a confounding factor in celiac disease: A 4-year follow-up family report. Epilepsy Behav Case Rep 2014; 2: 40-42.

3. Steele R; CRF. Diagnosis and management of coeliac disease in children. Postgrad Med J 2011; 87: 19-25.

4. Hadjivassiliou M, Sanders DS, Grünewald RA, Woodroofe N, Boscolo S, Aeschlimann D. Gluten sensitivity: from gut to brain. Lancet Neurol 2010; 9: 318-330.

5. Grossman G. Neurological complications of coeliac disease: what is the evidence? Pract Neurol 2008; 8: 77-89. 
6. Bürk K, Farecki ML, Lamprecht G, et al. Neurological Symptoms in Patients with Biopsy Proven Celiac Disease. Mov Disord 2009; 24: 2358-2362.

7. Freeman HJ. Neurological disorders in adult celiac disease. Can J Gastroenterol 2008; 22: 909-911.

8. Cakir D, Tosun A, Polat M, et al. Subclinical neurological abnormalities in children with celiac disease receiving a gluten-free diet. J Pediatr Gastroenterol Nutr 2007; 45: 366-369.

9. Luostarinen L, Himanen SL, Luostarinen M, Collin P, Pirttila T. Neuromuscular and sensory disturbances in patients with well treated coeliac disease. J Neurol Neurosurg Psychiatry 2003; 74: 490-494.

10. Cooke WT, Smith WT. Neurological disorders associated with adult coeliac disease. Brain 1966; 89: 683-722.

11. Briani C, Zara G, Alaedini A, et al. Neurological complications of celiac disease and autoimmune mechanisms: a prospective study. J Neuroimmunol 2008; 195: 171-175.

12. Volta U, De Giorgio R, Petrolini N, et al. Clinical findings and anti-neuronal antibodies in coeliac disease with neurological disorders. Scand J Gastroenterol 2002; 37: 1276-1281.

13. Luostarinen L, Pirttilä T, Collin P. Coeliac disease presenting with neurological disorders. Eur Neurol 1999; 42: 132-135.

14. Chapman RW, Laidlow JM, Colin-Jones D, et al. Increased prevalence of epilepsy in coeliac disease. $\mathrm{Br}$ Med J 1978; 2: 250-251.
15. Parisi P, Pietropaoli N, Ferretti A, et al. Role of the gluten-free diet on neurological-EEG findings and sleep disordered breathing in children with celiac disease. Seizure 2015; 25: 181-183.

16. Mavroudi A, Karatza E, Papastavrou L, Panteliadis C, Spiroglou K. Succesful treatment of epilepsy and celiac disease with gluten free diet. Pediatr Neurol 2005; 33: 292-295.

17. Collin P, Pirttila T, Nurmikko T, Somer $H$, Erile $T$, Keyrilainen O. Celiac disease, brain atrophy and dementia. Neurology 1991; 41: 372-375.

18. Hu WT, Murray JA, Greenaway MC, Parisi JE, Josephs KA. Cognitive impairment and celiac disease. Arch Neurol 2006; 63: 1440-1446.

19. Volta U, Ferri GG, De Giorgio R, et al. Sensorineural hearing loss and celiac disease: a coincidental finding. Can J Gastroenterol 2009; 23: 531-535.

20. Yıldırım S.V, Tiker F, Barutcu O, Cengiz N. Bilateral calcifications in the basal ganglia, and frontal and parietal lobes of a patient with coeliac disease. Pediatr Radiol 2005; 35: 710-712.

21. Beyenburg S, Scheid B, Schluter MD, Lagrezee HL. Chronic Progressive Leukoencephalopathy in adult celiac disease. Neurology 1998; 50: 820-822.

22. Cervio E, Volta U, Verri M, et al. Sera from patients with celiac disease and neurologic disorders evoke a mitochondrial-dependent apoptosis in vitro. Gastroenterology 2007; 133: 195-206. 